\title{
Assessment of Rainfall and Temperature Variability on Maize Production in Kaduna State
}

\author{
Aganbi Blessing ${ }^{a^{*}}$, Ifeka Adolphus ${ }^{\mathrm{b}}$ and Iyop Pam Juliana ${ }^{\mathrm{c}}$ \\ okpakoblessing@gmail.com \\ ${ }^{a}$ Nigerian Meteorological Agency, Abuja, Nigeria. \\ ${ }^{\mathrm{b}}$ Federal University of Technology Akure, Ondo State, Nigeria. \\ ${ }^{\mathrm{c}}$ National Centre for Remote Sensing, Jos, Nigeria.
}

\begin{abstract}
Rainfall and temperature are important requirements in crop production. Any variation in the distribution of these elements have marked influence on the productivity of most crops including maize. This study assessed rainfall and temperature variability on maize production from 1999 to 2016 in Kaduna State, Nigeria. Data for this study were obtained mostly from secondary sources. These data include temperature, rainfall and maize production which were collected from Nigerian Meteorological Agency (NiMet), National Bureau of Statistic (NBS) and the Kaduna State Agricultural Development Projects (KADP). Results are presented and discussed by the use of mean, mean departures, regression and correlation. To ascertain the annual trend in the meteorological parameters, a statistical t-test was carried out at the 1 and 5\% levels of significance. An increasing trend in rainfall and temperature was observed with early onset and cessation dates although only temperature was significant at the 1 and $5 \%$ level. To ensure uniformity in the analysis, the average annual yield per 100,000 hectares for each of the years were determined. Thereafter a multiple linear regression (MLR) model, that include maize yield as the dependent variable and the meteorological parameters, such as annual rainfall, average annual temperature, onset and cessation of rainfall as the dependent variables was developed using least square approach. Its overall significance was tested using the statistical f-test at the 1, 5 and $10 \%$ levels of significance and found to be significant. On that basis, each of the climatic parameter was tested and temperature and rainfall were found to be significant contributors to maize production. A model for predicting maize production was then developed and it was significant at 95 and $99 \%$ confidence level. The computed co-efficient of determination and linear correlation were $74.2 \%$ and 0.86 . The study recommends the use of the model developed to determine maize yield before the production season so as to equip farmers with fore knowledge of the expected yield and make alternative adjustments were necessary.
\end{abstract}

Keywords: Rainfall; Temperature; Maize Production

\subsection{Introduction}

Issues relating to changing rainfall patterns are becoming of great concern around the world. Reports of storms ravaging communities have become a recurring decima. The devastating impacts of climate change have gained global attention. Extreme rainfall events which where otherwise perennial occurrence have become more frequent (Olusegun et al., 2017). What's more frightening is the rate at which these events are predicted to occur more frequently in the coming years. 
Nigeria has witnessed significant climate variability which has resulted in extreme weather events such as flood that dislocated socio-economic activities across the country with the agricultural sector worse hit (NiMet, 2018). Between 2012 and 2018, there were several reports of flood episodes arising from higher precipitation amounts and, in some cases, poor drainages (NiMet, 2018). Increasing flood risk has been recognised as the most important threat to the environment and the agricultural sector in Nigeria.

There is a growing concern that over the coming decade, if nothing is done to reduce greenhouse gas emission, higher temperatures and changing precipitation levels are expected and will be unfavourable to crop growth and yield in many regions and countries of the world including Nigeria (Yusuf et al., 2008), particularly because of our poor coping mechanism viz-a-vis the inadequate adaptation and mitigation mechanism. Furthermore, there are projections that crop yield in Africa may fall by $10-20 \%$ by 2050 or even up to as low as $50 \%$ due to the impacts of climate change and or variability. This is so because the agricultural sector in Africa is mainly rain-fed (Jones and Thornton, 2003) that is mainly dependent of rainfall. One of such crops projected to be affected is maize. Maize according to the release by the Food and Agricultural organisation in terms of sensitivity to climatic variables has been ranged in the range of highly sensitive crop to moisture. Consequently, any deviation in rainfall and temperature across production zones, is likely to have a direct impact on the yield of the crop.

Maize is a major staple food in Sub-Saharan Africa, covering nearly 27 million hectares of land and accounts for 30\% of the total area under cereal cultivation in Africa, with 19\% in West Africa, 61\% in Central Africa, 29\% in Eastern Africa and 65\% in Southern Africa (FAO, 2010). In Nigeria, maize stands out as one of the most consumed staple foods, it is relatively cheap, serves a major food, also as feed grain, fodder among other important uses. In a related development, (Diallo et al., 1989) found that the availability of adequate rainfall is by far the most limiting factor in maize production in Sub-Saharan Africa. Rainfall is becoming unpredictable, both in timing and volume (Brett, 2009), areas which were regarded in time past as drier terrain are becoming wetter, conversely, wetter areas are becoming drier (Odekunle et al., 2008, Olusegun et al., 2017). In a report released by the National Emergency Management Agency (NEMA, 2017), it posited that the agricultural sector in Nigeria have suffered great losses resulting from extreme events such as flood leaving several farm lands inundated. Generally, there has been observed changes in the intensity, frequency and duration of rainfall with high spatio-temporal variation across Northern Nigeria (Olusegun et al., 2017; Oladipo, 1993a).

Recent research has shown that rainfall in the Sudano-Sahelian region have shown a shift towards wetter periods (Olusegun et al., 2017), especially after the drought observed in the 1970s to recovery period in the 1980s and beyond the year 2000 where significant rainfall amount were reported around the Sahel region. Worthy of note is the common knowledge that maize production in Nigeria particularly in commercial quantity is more predominant over the SudanoSahelian region of which Kaduna State is located. Therefore, following the growing concern particularly in the observed changes in rainfall onset, cessation dates, intensity and frequency and the high sensitivity of maize plant to moisture coupled with the fact that maize is a major staple food around the country, it becomes imperative to 
understand the rainfall and temperature trend around Kaduna State, with a view to providing scientific insight on how to better take advantage of these observed changes to ensure improved productivity. Additionally, there are further concerns following researches that have proven that adoption of high-yielding varieties, uniform planting practices and simultaneous timing of field operations have left the agricultural sector more subject to the vagaries of weather especially in developing countries, further works also have proven that a $1^{\circ} \mathrm{C}$ increase in global temperature will lead to reduced productivity in some cultivated to the tune of 17\% in maize and Soya beans (Allen 2010 and Thompson, 2005).

Moreover, this study will not only provide insight to the rainfall and temperature pattern in Kaduna State, but will further improve scientific knowledge by providing models in which farmers can apply to determine likely production outputs in the production year and possibly encourage farmers to explore other cultural practices that can be improved to enhance maize output where applicable.

\subsection{Study Area}

Kaduna State is located at latitude $10.6^{\circ} \mathrm{N}$ and longitude $7.45^{\circ} \mathrm{N}$. It shares borders with Zamfara, Katsina, Niger, Kano, Bauchi and Plateau States (Figure 1). The state occupies approximately 48,473.2 square kilometres and has a population of more than 6 million people (NPC, 2006). Major rivers include; River Kaduna, River Wonderful Kafanchan, River Kagom, River Gurara and Galma. Over $70 \%$ of the population in Kaduna state are engaged in agricultural production, most of which is dependent on rainfall. The state has two major seasons, the wet and the dry season. Average rainfall is about $1016 \mathrm{~mm}$. 


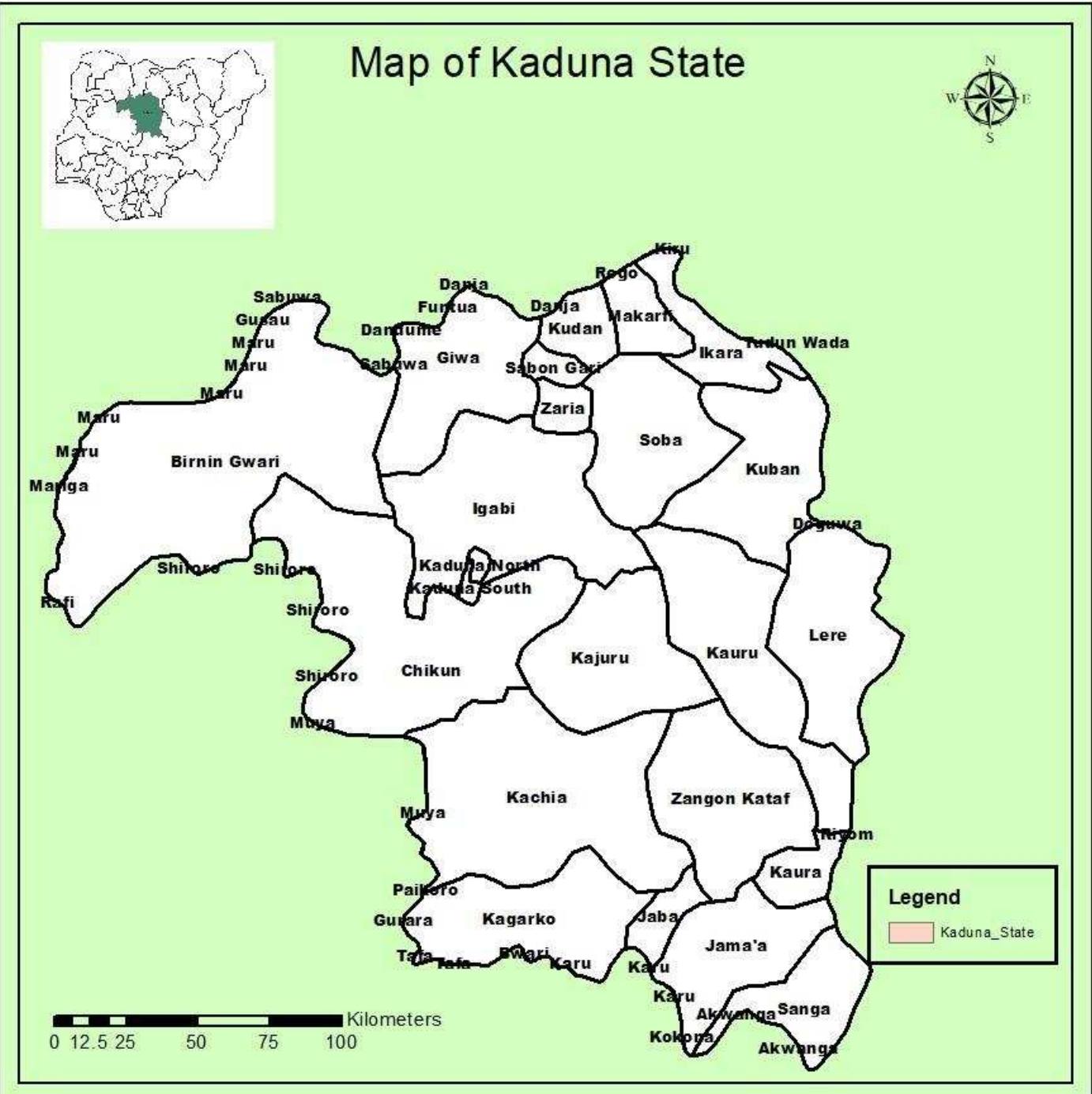

Figure 1: Map of Kaduna State 


\subsection{Materials and Methods}

Quality controlled data for rainfall and temperature were obtained from the Nigerian Meteorological Agency for the period 1999-2016. Additionally, crop data for maize production were obtained from the Kaduna State Agricultural Development projects (KADP) and the National Bureau of Statistics for the same period.

The data points were aggregated into their monthly and subsequently annual values in order to investigate the trends therein. Using the following expressions,

monthly rainfall $R_{j}=\sum_{i=1}^{l} R_{i j k} \ldots \ldots,[1]$

, where $\quad R_{i j k}$ is the rainfall on the $i^{\text {th }}$ day of the $j^{\text {th }}$ month of the $k$ th $y e a r ; l=30$ or $31 ;$ and $i=$ $1,2,3 \ldots . . . l ; l=30$ or 31

annual rainfall, $R_{k}=\sum_{i=1}^{m} R_{j k} \ldots \ldots .[2]$,

$\mathrm{j}=1,2,3 \ldots 1, \mathrm{~m}=12$, and $\mathrm{k}=1999,2000 \ldots . .2016$

The standardized annual precipitation index for this rainfall distribution was computed using the equation

$$
\operatorname{spi}\left(R_{k}\right)=\frac{R_{k-} \bar{R}}{\partial\left(R_{k}\right)}
$$

where $R_{k}$ is the annual rainfall, $\bar{R}$ and $\partial\left(R_{k}\right)$ are the mean annual rainfall and standard deviation respectively and are given by:

$\bar{R}=1 / n \sum_{k=1}^{n} R_{k}, \quad$ and $\partial\left(R_{k}\right)=\sqrt{1 / n \sum_{k=1}^{n} \frac{\left(R_{k-} \bar{R}\right)^{2}}{\partial\left(R_{k}\right)}} \ldots \ldots$

where $k=1999,2000,2016$, or $n=2016$

Similarly, the average daily temperature was computed as

$T_{k}=1 / l \sum_{i=1}^{l} T_{i k}$

Where $l=365$ or 366

$T_{k}$ is the average yearly temperature of the kth year; $l=365$ or 366 . This was then used to compute the long term yearly average temperature given by 
$\bar{T}=1 / m / \sum_{k=1981}^{m} T_{k} \ldots \ldots[6]$

where $k=1999,2000 \ldots \ldots 2016$

The standardized temperature anomaly for each of the 18 years was then computed using the expression

$$
\operatorname{spi}\left(T_{k}\right)=\frac{T_{k-} \bar{T}}{\partial\left(T_{k}\right)}
$$

where $T_{k}$ is the average yearly temperature, $\bar{T}$ and $\partial\left(T_{k}\right)$ are the longterm average

yearly temperature and standard deviation of $T_{k}$ respectively, and are given by:

$\bar{T}=1 / n \sum_{k=1}^{n} T_{k}[8]$, and $\partial\left(T_{k}\right)=\sqrt{1 / n \sum_{k=1}^{n} \frac{\left(T_{k-} \bar{T}\right)^{2}}{\partial\left(T_{k}\right)}} \ldots[$ [9] with $k$ as defined

Trend analysis test was then carried on the annual rainfall and average annual temperature (through the years 19992016) as computed in [2] and [5] respectively in order to ascertain the significance or otherwise of the trend therein at the 1,5 and $10 \%$ levels.

The trend test was performed using parametric the $t$ test given by the expression $t=\frac{x-\bar{x}}{\partial}$.

Furthermore, in order to determine the onset and cessation of rainfall, the following the Walter's formulation, with some modifications by Olaniran (1983), and accepted to be highly reliable amongst other methods was employed:

It is given as

Onset $/$ End $=\frac{D M}{T M} *(51-A P)$

Where $D M=$ number of days in the month containning the onset

$$
T M=\text { total rainfall for the month in which accumulated rainfall exceeds } 51 \mathrm{~mm}
$$

And

$A P=$ accumulated rainfall of previous months just before the month in refrence 
$51 \mathrm{~mm}=$ the threshold of rainfall for both Onset/End month.

However, an important criterion here is that the date chosen as the onset must not be accompanied by 14 consecutive days of dry spell as this invalidates the definition, thus where such is found to have occurred the next month not accompanied by up to 14 days of dry spell is considered the onset date.

The expression is applied in the reverse order to determine the cessation date cumulating the rainfall from the month of December towards January.

Additionally, to determine the relationship between maize production as the dependent variable and climatic derivatives such as rainfall, temperature, onset, cessation and the length of the growing season as the independent variable, a multiple linear regression model was constructed. Subsequently it was tested using f-test and t-test to ascertain the significance or otherwise:

i. of the relationship tentative, it supported the investigation to establish whether or not the a MLR relationship exists between the variables in the first place

ii. of each of the independent variables, i.e. onset, cessation, annual rainfall and temperature; this served to indicate which of the variables contribute significantly or not to yield.

The general form of a multiple linear regression model is a relationship between dependent and independent variables or between response and predictor variables which is given by:

$$
y_{i}=\beta_{0}+\beta_{1} x_{i 1}+\beta_{2} x_{i 2}+\cdots \beta_{k} x_{i k} \cdots \cdots \cdots \cdots[11]
$$

And this was adopted with all the $y_{i}(i=1,2, \ldots \ldots n, k$ is any whole $n u \square b e r)$ as the dependent variable and the $\beta^{\prime} s$ as the coefficients of the independent variables $x_{i}(i=1,2,3, \ldots k)$, ordinary least square optimization techniques can be employed to estimate the coefficients of this function. (Ezequiel, 2013).

The process of optimization is given as:

$$
Y=X \beta \ldots \ldots \ldots 11, \text { here } Y \text { is the vector }\left(\begin{array}{c}
y_{1} \\
y_{2} \\
\cdot \\
\cdot \\
\cdot \\
y_{n}
\end{array}\right), X=\left(x_{i j}, i=1,2,3 \ldots n, j=1,2, . . k\right)
$$

here $X$ is a vector or matrix of values as already $\square$ efined and 
$\beta$ is a vector of the coefficients given as $\beta=\left(\begin{array}{c}\beta_{0} \\ \beta_{1} \\ \cdot \\ \cdot \\ \beta_{n}\end{array}\right)$

According to ordinary least squares optimization technique the coefficients can be estimated as

$\hat{\beta}=\left(X^{T} X\right)^{-1} X^{T} Y$

Now in this research containing the four independent variables aforementioned, by adjusting [12]; that is by substituting $n=18$ and $k=4$ into [10], the tentative model becomes

$y_{i}=\beta_{0}+\beta_{1} x_{i 1}+\square_{2} x_{i 2}+\beta_{3} x_{i 3}+\beta_{4} x_{i 4}(i=1,2, \ldots 18$ years $)$

With $x_{i 1}, x_{i 2}, x_{i 3}$ and $x_{i 4}$; As onset, length of growing season lgs, annual temperature and annual rainfall respectively,

$\beta_{1}, \beta_{2}, \beta_{3}$, and $\beta_{4}$ are their respective coefficients

Equation 12 was used to estimate the coefficients. This was done by using a software model designed in Microsoft excel into which the methodology (ordinary least square optimization technique) for solving the general [eqn 10] MLR model is embedded.

As have been mentioned, having constructed the tentative MLR relationship, the significance or otherwise of the MLR relationship as a whole and the individual climatic variables will be tested using f-test or t-test

\subsection{Test for the Significance of the Multiple Linear Regression.}

The significance or otherwise of the relationship and the individual climatic variables were subjected to f-test to ascertain their significance or otherwise. Under this subject matter two types of tests were carried out viz: 
i. Test the significance or otherwise of the multiple linear regression as a whole to see if such a relationship exists in the first instance

ii. Test the individual parameters with a view to ascertaining their significance or otherwise; to help determine the climatic parameters that would be retained in the relationship, if and only if the first test proves the existence of an MLR relationship.

Now in both cases a null hypothesis was proposed under the f-distribution, and in the first case it is given by

$\mathrm{H}_{0}: \beta_{4}=\beta_{3}=\beta_{2}=\beta_{1}=0 \ldots \ldots ;$ here it states that all the coefficients are equal to zero

$\mathrm{H}_{1}: \beta_{j} \neq 0(j=1,2,3,4)$; at least there exists one a coefficient that is not equal to zero.

$\mathrm{H}_{0}: \beta_{k}=0$, where $k=1$ or 2 or 3 or 4

$\mathrm{H}_{1}: \beta_{k} \neq 0(k=1$ or 2 or 3 or 4$)$

According to this procedure, a statistic known as F-ratio or simply F-statistic would be computed. This statistic is also an independent random variable and is given as in [14]. Similarly, in the case of $\mathrm{H}_{0}: \beta_{k}=0$, the statistic can also be considered to have a t-distribution, thus the significance of each of the parameters was tested under t-test.

$$
\begin{aligned}
& \mathrm{F}=\frac{\left(R_{U R}^{2}-R_{R}^{2}\right) / q}{\frac{1-R_{U R}^{2}}{n}-k-1}[14 \mathrm{a}] \\
& t=\frac{\beta_{k}-0}{\left(\beta_{e}\right)} \ldots[14 b]
\end{aligned}
$$

where here $\beta_{k}$ and $\beta_{e}$ are the individual

\section{parameters and their associated standard errors respecti $\square$ ely}

When the f-ratio was computed it was then compared with its critical value corresponding to

Fq,n-k. With $\mathrm{n}$ as the sample size or number of data points, which is 18 in this study, $\mathrm{q}$ is the number of degrees of freedom associated the numerator of eqn 14 while (n-k) is the number of degrees of freedom corresponding to the denominator. Furthermore, $\mathrm{k}$ is the number of parameters in the unrestricted model, while $\mathrm{q}$ is simply the number of parameters whose significance or otherwise at the given test point, the study seeks to ascertain at the $1 \%, 5 \%$ and $10 \%$ level of significance. $\mathrm{R}_{\mathrm{UR}}{ }^{2}$ is the R-square associated with the model in its original form or the tentative model and it is termed unrestricted, UR, while $\mathrm{R}_{\mathrm{R}}{ }^{2}$ is the R-square corresponding to the model in which the conditions in the null hypothesis have been imposed, and is thus termed restricted. At a significant level of $1 \%$ and $5 \%$ the computed Fstatistic statistic is compared with its critical value, and if found to be less than this critical value the null hypothesis would not be rejected and it would be concluded that the coefficient is not significant at the 10, 5 and $1 \%$ level of significance., if otherwise it would be concluded that the coefficients are significant at the 1 or $5 \%$ level. 
The test for the individual coefficient is similar except in this case we would be carrying out the test taking the coefficients one at a time. Similarly, the t-statistic having been computed using eqn $14 \mathrm{~b}$, its values is compared to its critical value with (n-1) degrees of freedom at the 10,5 and $1 \%$ level of significance.

\subsection{Test for the Significance of the Multiple Linear Regression Using p- values}

The level of significance of each of the climatic parameters can also be ascertained using their respective p values. A $\mathrm{p}$-value is simply the lowest level of significance at which a null hypothesis can be rejected. The $\mathrm{p}$ value is invariably associated with the sample, which is why a sample has to be drawn before it is computed. The p-value can also be defined as the probability, given that the null hypothesis true, of obtaining a result equal to or more extreme than what was actually observe. In other words, it is the probability that the statistic under investigation is equal to or more extreme than what was actually observed. It is also the critical or exact probability of making a type I error. Type I error is the error made by rejecting the null hypothesis when it is true. Thus, whenever the p-value associated to a parameter under investigation is higher than the imposed level of significance, the null hypothesis can be rejected, or more particularly in this study we can then conclude that the parameter is significant. If the p-value is however greater than the level of significance, the null hypothesis cannot be rejected.

\subsection{Coefficient of Determination of Multiple Linear Regression Model}

A very good indicator of the performance of a model is an index called the co-efficient of determination. According to Wikipedia on the subjected matter, last edited on $20^{\text {th }}$ of March, 2018, the co-efficient of determination is a statistical index that computes and quantifies the amount of variation in the values of a variable or parameter $\left(\mathrm{y}_{\mathrm{i}}\right)$ that can be explained by output or forecast, often times generated from a model ( $\left.\mathrm{y}_{\mathrm{i} \text { model }}\right)$, intended to mimic the values and variations of the parameter. Mathematically it can be computed with the expression:

$$
\mathrm{R}^{2}=\frac{\sum_{\mathrm{i}=1}^{\mathrm{n}}\left(\mathrm{y}_{\text {model }}-\overline{\mathrm{y}}\right)^{2}}{\sum_{\mathrm{i}=1}^{\mathrm{n}}\left(\mathrm{y}_{\mathrm{i}}-\overline{\mathrm{y}}\right)^{2}} \ldots \ldots \ldots \ldots[15]
$$

In relation to the study, it can simply be described as the amount of variation in the actual maize production, within the period under review ( $i=1999,2000, \ldots .2016$ ), explained or replicated by the model using only the significant parameters. Additionally, having determined the model for predicting maize, a correlation analysis was carried out to ascertain the significance of the linear relationship between actual production figures and forecast. The equation is as presented thus; 


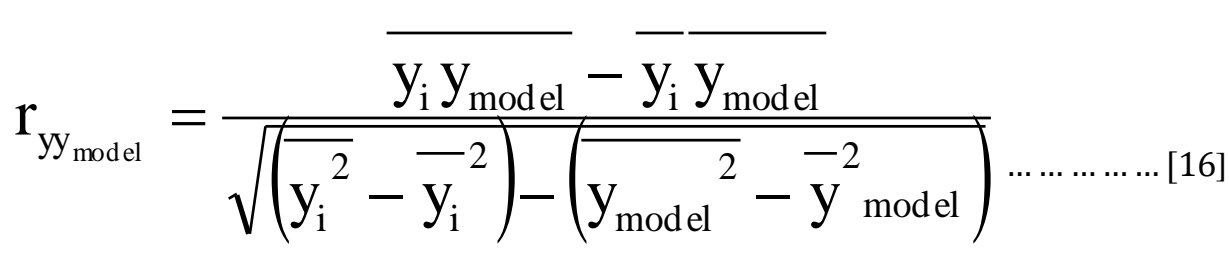

With $y_{i}$ as the actual maize production, and $\mathrm{y}_{\text {model }}$ as the MLR model for the forecast production, $\mathbf{r}_{\mathrm{yy}_{\text {model }}}$ is the coefficient of correlation between maize production and the climatic parameters.

The standard error that is likely to result from using the MLR model to determine or forecast yield was computed. The standard error is simply the error that could result from using the model to forecast yield for any given year. This is why the formula for its computation is expressed as:

$$
\mathrm{s}_{\mathrm{e}}=\sqrt{\sum_{\mathrm{i}=1}^{18} \frac{\left(\mathrm{y}_{\mathrm{i}}-\mathrm{y}_{\text {modeli }}\right)^{2}}{(\mathrm{n}-2)}} \ldots \ldots \ldots[\text { [17] }
$$

$\mathrm{y}_{\text {modeli }}$ is the output from the model, $\mathrm{y}_{\mathrm{i}}$ is the actual output,

$$
i=1,2,3, \ldots . .18 \text { corresponding to years } 1999 \text { to } 2016
$$

\subsection{RESULTS AND DISCUSSION}

\subsection{Temperature and Rainfall Trend/Variability over Kaduna State}

\subsubsection{Temperature Variation in Kaduna State}

The temperature distribution during the period of study is presented in figure 2. Between 1999 and 2016, there has been progressive increase in temperature values in Kaduna State. Lowest average maximum temperature values were observed in 2001 and 2007 respectively, with a mean value of $31.7^{\circ} \mathrm{C}$, while highest observed air temperature of $33.0^{\circ} \mathrm{C}$ was recorded in 2016 . Average air temperature for the period was $32.1^{\circ} \mathrm{C}$. The results revealed that on the average per decade, an increase of $0.31^{\circ} \mathrm{C}$ of temperature was recorded in the study area. The co-efficient of interannual temperature distribution over Kaduna was found to be $1 \%$. Fitted to a linear trend line, an increasing trend was observed in the study area. 


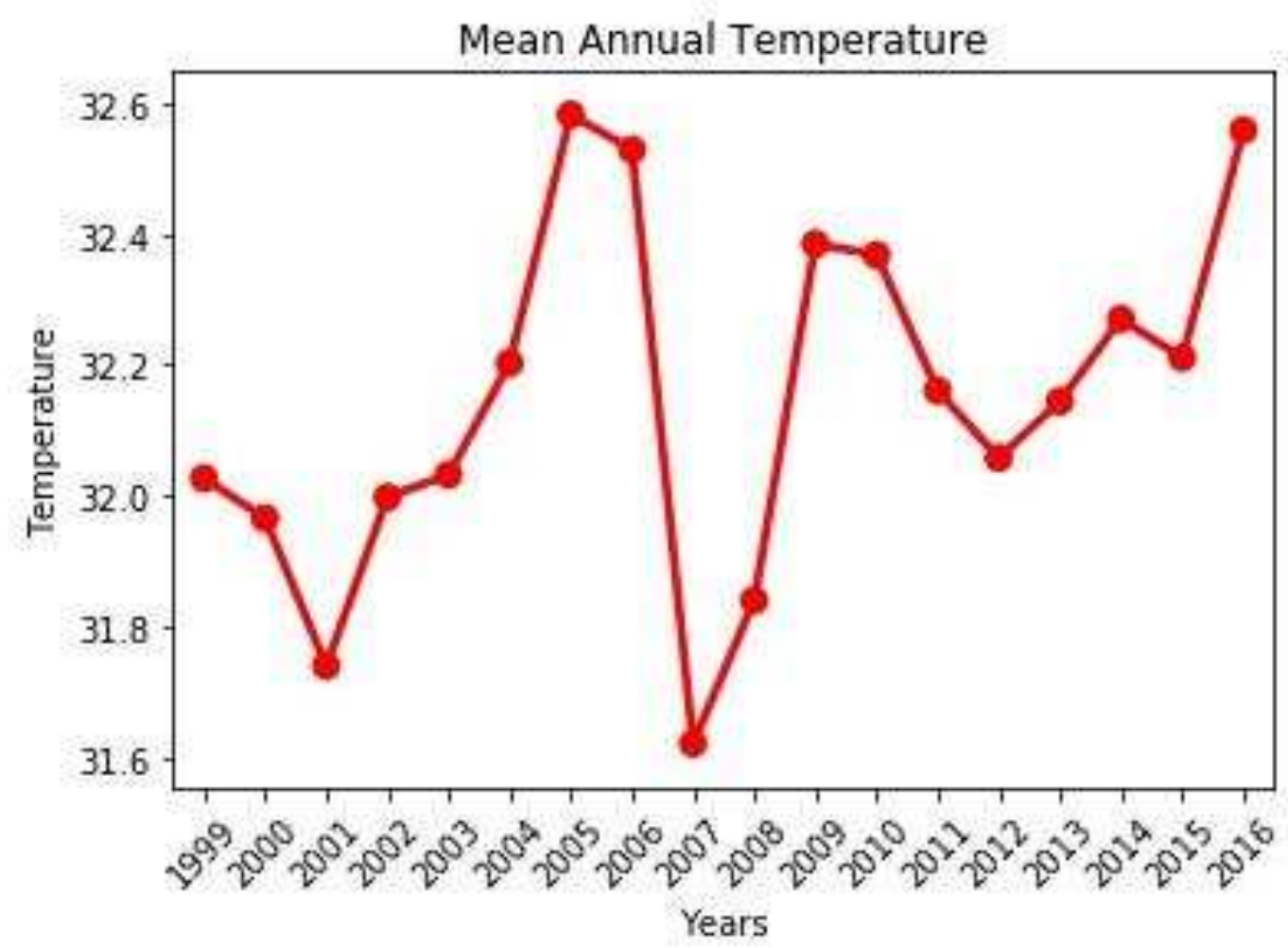

Figure 2: Temporal Distribution of air temperature over Kaduna StateSource: Research Data

\subsubsection{Temperature Departure in Kaduna State}

The temperature anomaly over Kaduna state is highlighted in figure 3. Overall, the net inter-annual variability in air temperature from 1999-2016, as shown by the trend line, was found to exhibit a significant upward trend at the 5\% level of significant under t-test, with a calculated value of 2.6234. Additionally, the temperature departure showed a significant upward trend during the period under review, these findings are also supported by the pattern observed in the annual temperature departure plot on figure 3. Here it can be observed that temporal temperature distribution showed a decrease between 1999 and 2001 with values of between -0.5 and -1.8 respectively. However, between 2002 and 2006, an increase in temperature was observed in Kaduna State. During the period 1999-2016, the highest observed difference was in 2016 with an anomaly of $+2.39^{\circ} \mathrm{C}$ with lowest deviation of $-1.75^{\circ} \mathrm{C}$ observed in 2001 . The observed difference in the temperature deviation for 2016 may not be unconnected to the observed high temperatures recorded in 2016 which the World Meteorological Organisation (WMO) adjourned to be the hottest year in record since pre-industrial era. This is also supported by the report released by NiMet in 2016 where higher than normal temperatures were reported across the country with episodes of heat waves. Some of these observed differences may not be unconnected to climate change and or variability resulting from increased anthropogenic activities. 


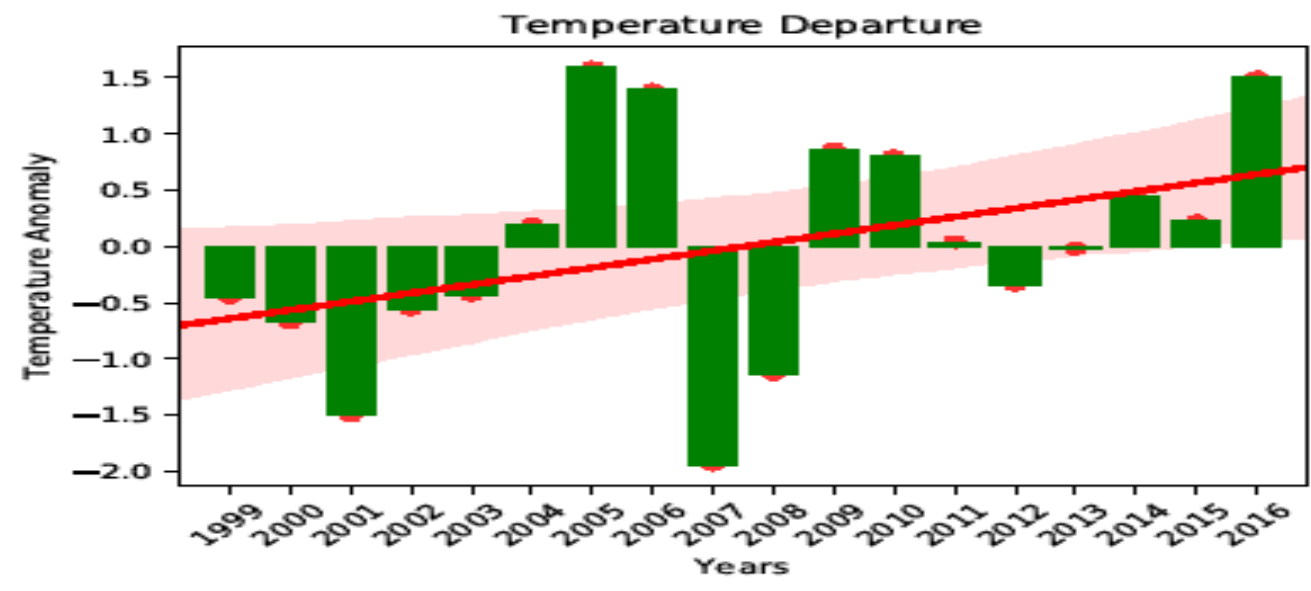

Figure 3: Annual Mean Air Temperature Departure over Kaduna State

Source: Research Data

\subsubsection{Rainfall Distribution over Kaduna State}

The annual distribution of rainfall is shown on figure 4, where there is a progressive increase in rainfall amount during the period of study, although between 2005 and 2008, a slight decline was observed. Rainfall amount ranged between lowest value of $793.4 \mathrm{~mm}$ in 2008 , and highest value of $1658.9 \mathrm{~mm}$ in 2014. During the period, average annual rainfall amount was $1279.4 \mathrm{~mm}$. There was a high coefficient of inter annual variation of about $21 \%$. This observation is supported by those of Ayansina et al., (2009) who investigated seasonal rainfall variability in the Guinea Savannah part of Nigeria and found that there was an increase in rainfall variability in the zone which he attributed to climate change. The observed rainfall pattern during the period generally implies that rainfall is not stable and this may likely have implications on yearly maize crop production in the state.

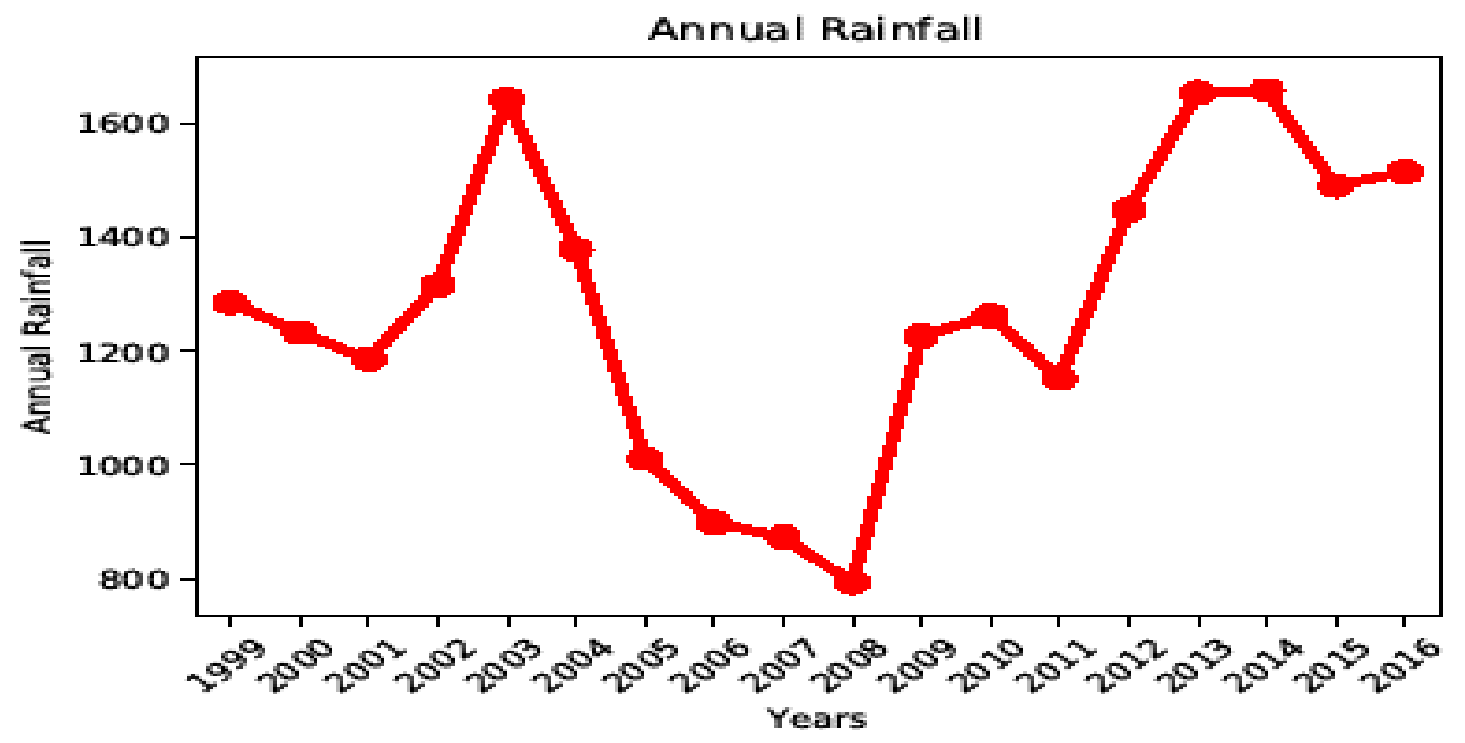

Figure 4: Temporal Distribution of Rainfall over Kaduna State 
Source: Research Data

\subsubsection{Distribution of Rainfall Departure in Kaduna State}

The standardized precipitation index between 1999-2016 is shown in figure 5. Rainfall distribution over Kaduna state for the period showed an increase in rainfall amount between 1999 and 2003, after which below normal rainfall amounts were observed between 2005 and 2008. Rainfall amounts shows some recovery between 2009 and 2016 with positive anomaly observed during the period. Over all, there was a marginal increase in rainfall though not statistically significant (1.4499) with a high inter annual variability of about $21 \%$. These observations are in line with the study undertaken by Kandji et al., (2006) where he found a strong variation and an irregular pattern of rainfall over northern Nigeria. Additionally, Oladipo (1993a); and FRN (2000), also recorded a high spatio-temporal variation in rainfall with an inter-annual variability of between 15 and 20\% over northern Nigeria. These observations are also supported by those of Aremu et al., (2017), who also noticed an increase in rainfall over Kaduna, although not statistically significant. By this inference, rainfall amount may not differ much and so farmers are expected to maximise the growing season in other to optimise productivity otherwise significant increase in production may not be achieved.

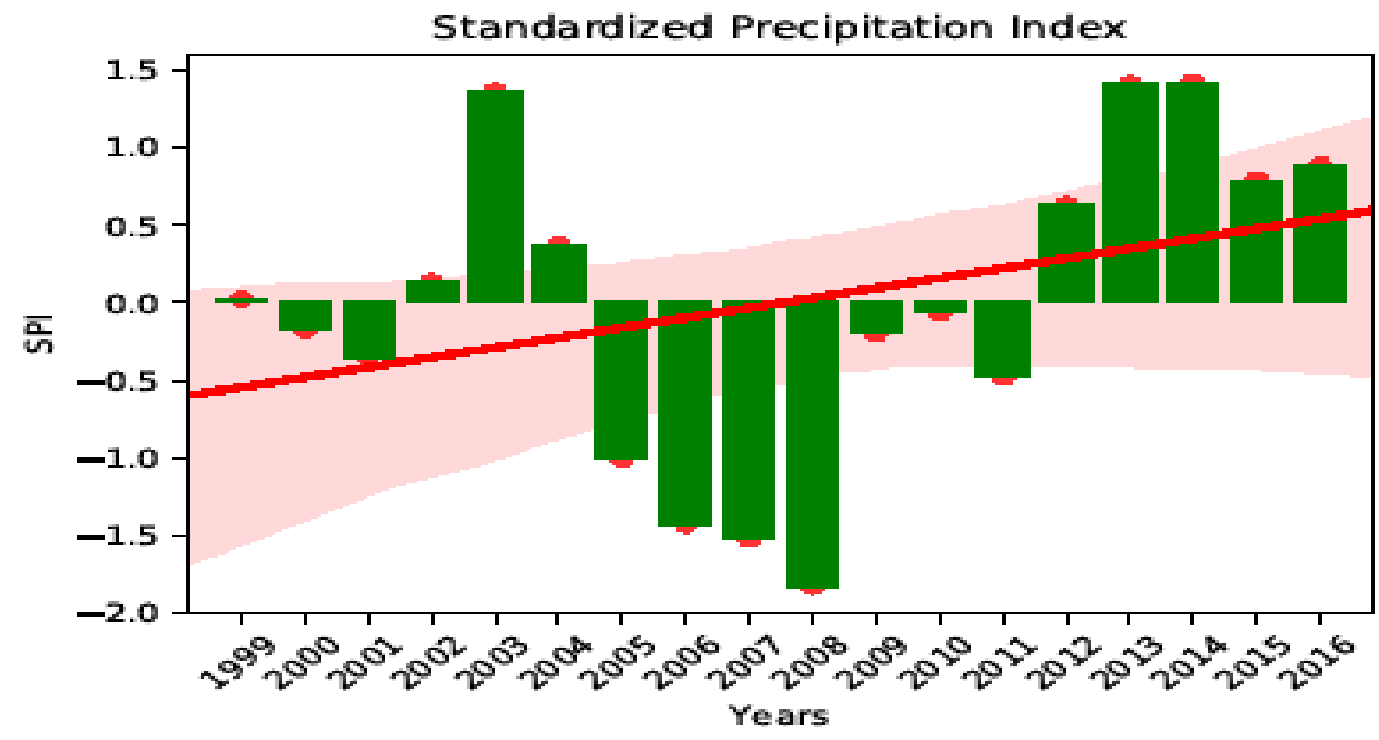

Figure 5: Standardized Precipitation Index for Kaduna State

Source: Research Data

4.2 Determination of the Onset, Cessation and Length of the Growing Season (LGS) and their Departure from the Average

\subsubsection{Onset Date}


The onset dates in Kaduna State for the period under study is presented on Table 1. The lowest and latest onset dates are observed to have occurred on the $17^{\text {th }}$ March, 2016 and $13^{\text {th }}$ of May, 2006 respectively. Subjected to statistical test, the departure in onset dates in Kaduna is found to be statistically not significant at the $1 \%$ and $5 \%$ levels as shown on table 2. The implication is that earlier onset dates have been, more or less, observed as supported in the onset departure plot on figure 6, especially in 2016 with the earliest onset date. These findings are supported by reports from the Nigerian Meteorological Agency NiMet in its annual Seasonal Rainfall Prediction (NiMet, 2018) where it revealed that onset dates have become earlier than normal, especially in recent years. Fitted to a linear trend line, a downward trend in onset dates can be observed. Since the onset dates come earlier, farmers are advised to commence farming activities once onset is established and should make improvement from traditional practice if any meaningful increase in maize productivity is to be achieved.

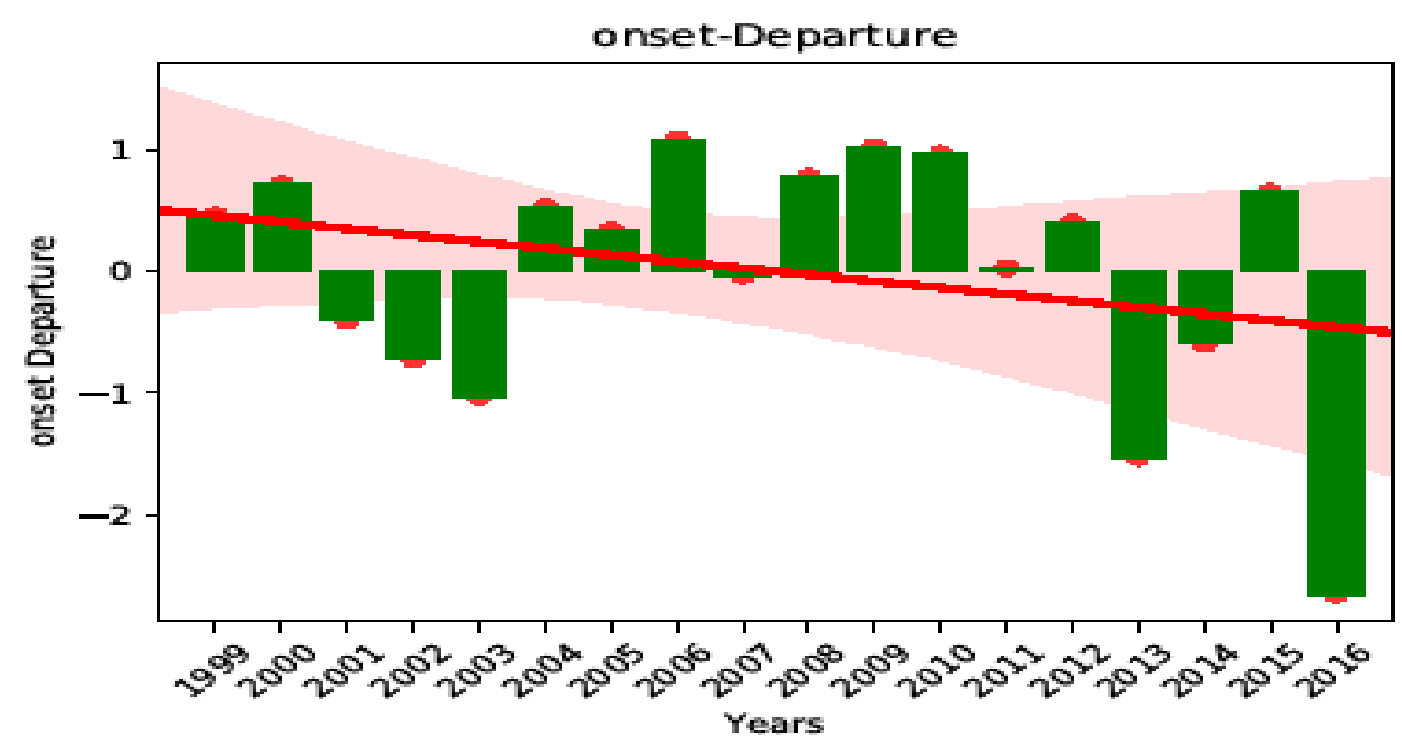

Figure 6: Onset Deviation for the period 1999-2016

Source: Research Data

\subsubsection{Cessation Date}

The cessation dates for rainfall in Kaduna is presented on Table 2. On the average, although there has been changes in the cessation dates over Kaduna, these changes have also not been statistically significant (at the 1 and 5\% levels) based on the results of the statistical trend test is shown on Table 2. However, in the last years (2014-2016), there has been early cessation of the rains. This implies that rainfall cessation date is otherwise earlier experienced, consequently, farmers are to take note and adjust farm management practices accordingly.

An analysis of the departure in cessation dates as presented in figure 7 shows cases of early cessation when compared to the average cessation dates. The plots revealed a composite nature of both early cessation and late cessation in some 
cases with latest figures revealing an early cessation of the rains. This is also supported by reports from the NiMet on early cessation of the rains in parts of Nigeria (NiMet Climate Review, 2017). The dates for cessation are very critical to determining the length of the growing season and play a key role in determining the types of crops produced during the season. As with the onset dates, when fitted to a trend line, a downward slope is observed especially during the latter years of the study (2013-2016).

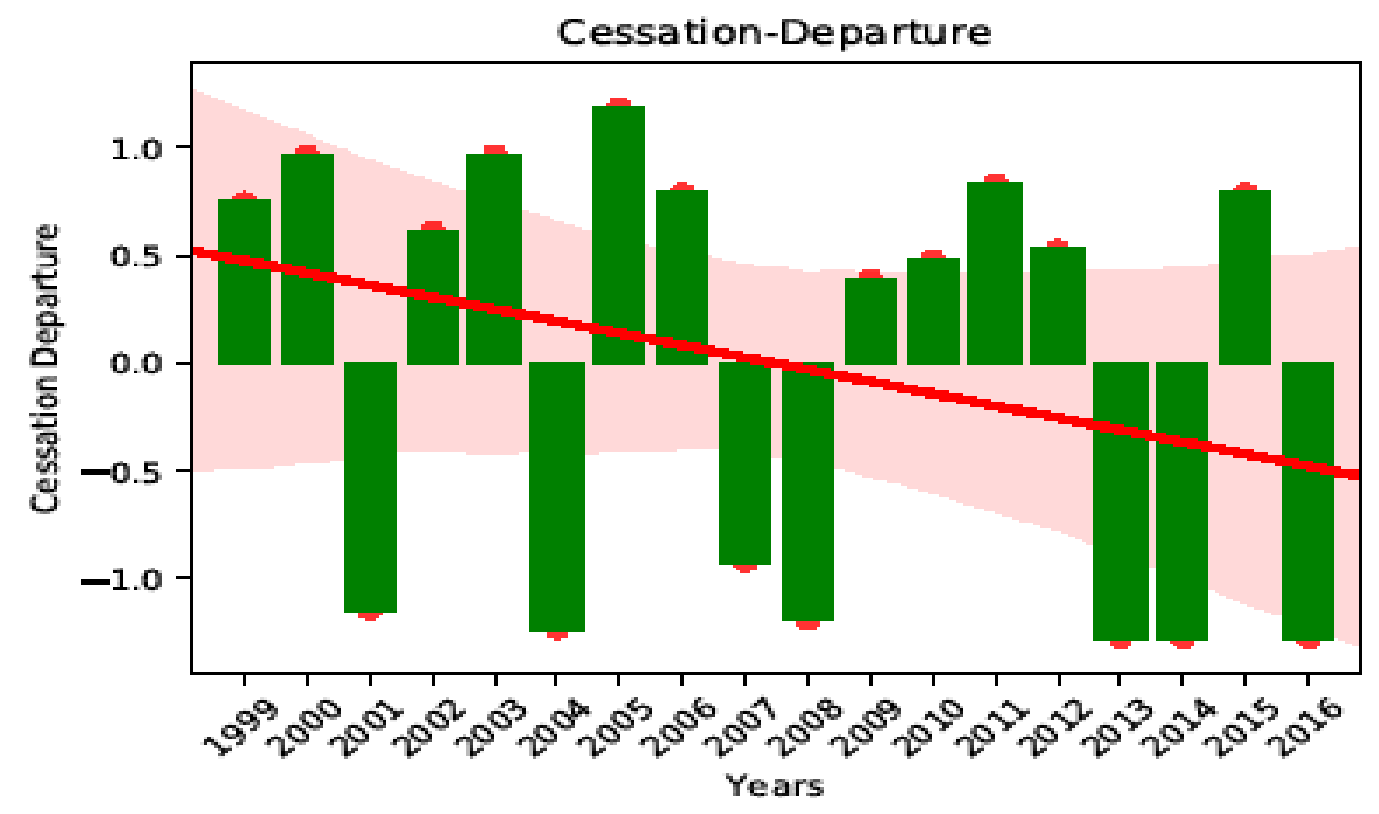

Figure 7: Cessation dates deviation for the period 1999-2016

Source: Research Data

\subsubsection{Length of the Growing Season (L.G.S)}

The result presented on table 1, shows that there is no significant change at the $1 \%, 5 \%$ and $10 \%$ level in the length of the growing season (LGS) during the period under review. However, a plot of the departure in the length of the growing season (LGS) as shown in figure 8, revealed that in 2001, 2004, 2007 and 2008, a remarkable decrease in LGS was observed, while in 2002, 2003, 2005, and 2014, an increase in LGS was observed. On the average, LGS was about One Hundred and Sixty days (160) during the period under review. 


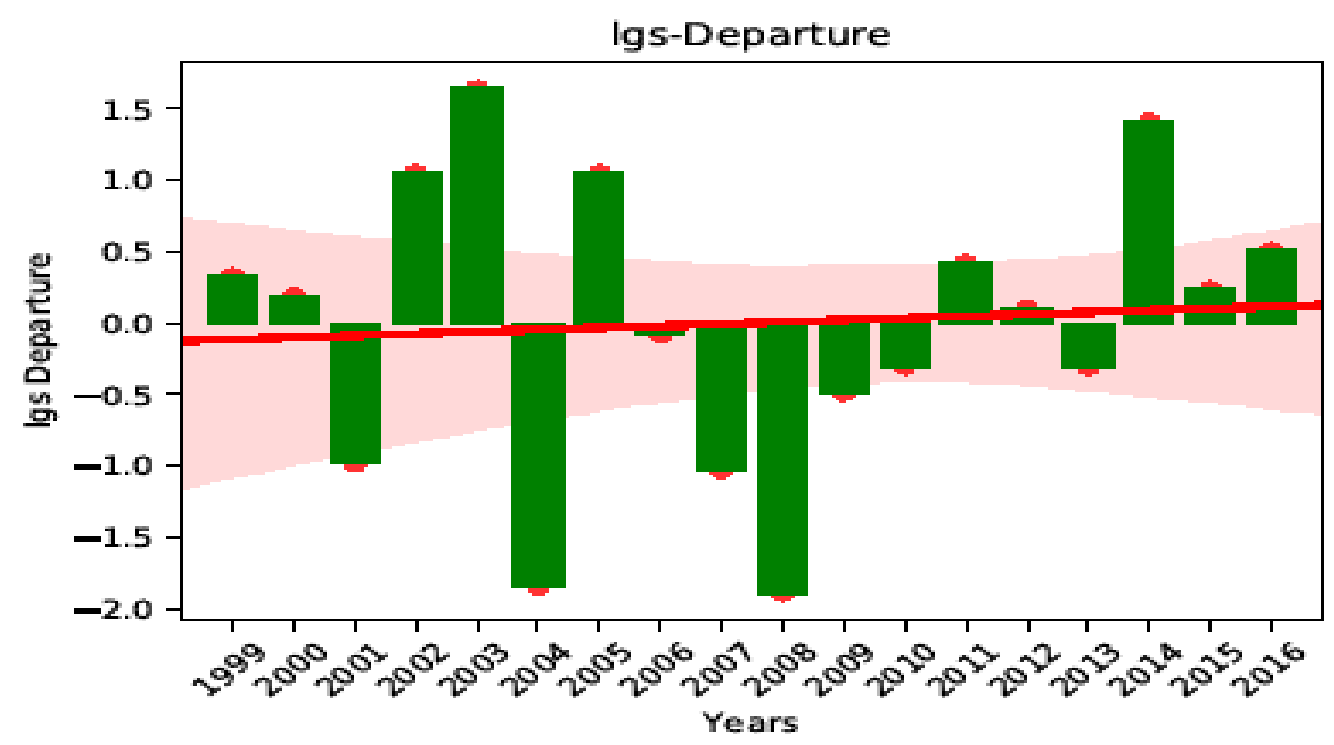

Figure 8: Length of the Growing Season Deviation for the period 1999-2016

The results for test for significance of the onset, cessation and length of the growing season and the associated dates are presented in the Table 1 and 2 respectively.

Table 1: Onset, Cessation and Length of the Growing Season

\begin{tabular}{cllc}
\hline Year & Onset & Cessation & $\begin{array}{c}\text { Length of the growing } \\
\text { season (days per year) }\end{array}$ \\
\hline 1999 & $3^{\text {rd }}$ May & $14^{\text {th }}$ October & 167 \\
2000 & $7^{\text {th }}$ May & $9^{\text {th }}$ October & 164 \\
2001 & 19 April) & $26^{\text {th }}$ September & 138 \\
2002 & 14 April & $17^{\text {th }}$ October & 183 \\
2003 & 20 April & $09^{\text {th }}$ October & 196 \\
2004 & $4^{\text {th }}$ May & $28^{\text {th }}$ September & 119 \\
2005 & 1 st May & $4^{\text {th }}$ October & 183 \\
2006 & $13^{\text {th }}$ May & $13^{\text {th }}$ October & 158 \\
2007 & 30 April & $21^{\text {st }}$ September & 137 \\
2008 & $8^{\text {th }}$ May & $27^{\text {th }}$ September & 118 \\
2009 & $20^{\text {th }}$ April & $22^{\text {th }}$ October & 149 \\
2010 & $11^{\text {th }}$ May & $20^{\text {th }}$ October & 153 \\
2011 & $26^{\text {th }}$ April & $12^{\text {th }}$ October & 169 \\
2012 & $25^{\text {th }}$ April & $19^{\text {th }}$ October & 162 \\
2013 & $1^{\text {st }}$ April & $29^{\text {th }}$ September & 153 \\
2014 & $14^{\text {th }}$ April & $29^{\text {th }}$ September & 191 \\
2015 & $6^{\text {th }}$ May & $13^{\text {th }}$ October & 165 \\
2016 & $17^{\text {th }}$ May & $29^{\text {th }}$ September & 171 \\
\hline
\end{tabular}

Source: Research data. 
Table 2 Test of Significance of Anomalies of Climatic Parameters

\begin{tabular}{|c|c|c|c|c|}
\hline Test & 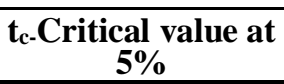 & 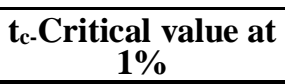 & $\mathrm{t}$ - calculated value & Remarks \\
\hline Rainfall & 2.1098 & 2.8982 & 1.4499 & NSS \\
\hline Onset & 2.1098 & 2.8982 & 1.2008 & NSS \\
\hline Cessation & 2.1098 & 2.8982 & 1.2544 & NSS \\
\hline LGS & 2.1098 & 2.8982 & 0.290144 & NSS \\
\hline Temperature & 2.1098 & 2.8982 & 2.6234 & $\mathrm{SS}$ at $5 \%$ \\
\hline
\end{tabular}

NSS** No statistically significant increase at 1 and 5\%, SS** statistically

significant increaseNote: if $t_{c}$ is greater than $t$, the change is not significant.

Source: Research data.

\subsection{The Relationship between Maize Production and the Climatic Parameters: The Multiple Linear}

\section{Regression (MLR) Model}

In this section the results of the multiple linear regression were derived involving maize yield as the independent variable and rainfall, temperature (temp), length of growing season (lgs) and the onset, all as independent variables. To ascertain the level of significance of the contributions of each of these climatic parameters to yield, an F-test was carried out at different levels of significance. The multiple linear regression model involving the four variables namely Rainfall, Temperature, Onset and the Length of the Growing Season, derived according to the approach adopted is:

$$
y i=-4519438.36-1804.89 x i 1-1735.94 x i 2+196420.04 x i 3-469.71 x i 4 \ldots[18]
$$

where $i$ is from 1 to 18 i.e (1999-2016), xi1 represents onset, $x \square 2$, length of growing season (lgs), xi3 temperature and xi4 anual rainfall, while yi represents maize yield respectively.

Thus, the coefficients in eqn 13 have been determined using the least squares approach clearly outlined by eqn 12 . However, it must be ascertained if the model is significant as to warrant concluding that it exists in the first place. This was done by testing the significance of all the parameters across significant levels $0.1,0.05$, and 0.01 .

\subsubsection{Significance of the Multiple Linear Regression model}

Significance of the whole MLR model was carried out to ascertain if a linear relationship exists between the yield and the other climatic parameters in the first place. This was carried out following the approach by Ezequiel Uriel (Universidad de Valencia Version: 09-2013) as outlined according to eqn 14.

Following eqn 14, the computed f-ratio was found to be 9.358 , while the critical value of the f-ratio was found to be 3.17 at 4 degrees of freedom for the numerator, and 13 degrees of freedom for the denominator and at $5 \%$ level of significance; the number of data points $\mathrm{n}$, is 18. Apparently, the computed f-ratio (9.358) is greater than its critical value (3.17) indicating that the model is significant at $5 \%$ level of significance. The significance of the model was also tested at $1 \%$ and $10 \%$ both of which agreed that the model is significant. Thus, at all levels of significance (1\%, 
$5 \%$ and $10 \%$ ) the f-test clearly demonstrated that the model is significant, in other words a linear relationship exists between maize yield and the four climatic variables. This is also backed by the associated p value $(0.09 \%)$, which is less than all the highlighted levels of significance, indicating that the null hypothesis $\left(\mathrm{H}_{0}\right.$, which states there is no relationship between maize and the climatic variables), can be rejected. However, the level of significance of each of these variables needs to be determined in order to ascertain the degree of their individual contributions to the yield relative to each other.

\subsubsection{Significance of the Individual Parameters}

To ascertain the significance or otherwise of the individual parameters in eqn18, the parameters were subjected to $f$ and t-test. The results are presented in tables 3-7 and 8-10. The results presented in the tables were derived employing two techniques to test for the significance of the parameters in the model (eqn 18). Both of the techniques are parametric involving f-ratio, t-ratio and p values, and the study maintained the hypothesis aforementioned in chapter three. In the first instance the parameters of the model were tested one after the other. For instance, in the test for the significance of temperature, three of the other parameters were retained in the model, thus at any given test point regardless of the parameter in question, three of the others were retained in the model. This approach generated the results in tables $(3$ $-4)$.

Under this scenario, at the significant levels $1 \%, 5 \%$ and $10 \%$, the f-ratio or f-statistic was computed from eqn $14 a$, and then compared with its critical value at q degrees of freedom in the numerator of the expression (eqn 14a) and n$\mathrm{k}$ degrees of freedom in the denominator. This approach proved that the onset and length of the growing season (LGS) are not significant at all the three chosen levels of significance (table 3 and 4).

Table 3: critical values for f-statistic at $\mathrm{n}-\mathrm{k}$ and $\mathrm{q}$ degrees of freedom (df) For the climatic parameters

\begin{tabular}{lccccc}
\hline \multirow{2}{*}{ Parameter } & \multicolumn{2}{c}{ Degrees of freedom(df) } & \multicolumn{2}{c}{ Critical values for f-statistic at: } \\
\cline { 2 - 6 } & $\mathbf{q}$ & $\mathbf{n - k}$ & $\mathbf{1 \%}$ & $\mathbf{5 \%}$ & $\mathbf{1 0 \%}$ \\
\hline ONSET (xi1) & 1 & 17 & 9.07 & 4.67 & 3.14 \\
LGS (xi2) & 1 & 17 & 9.07 & 4.67 & 3.14 \\
RAINFALL & 1 & 17 & 9.07 & 4.67 & 3.14 \\
(xi3) & 1 & & & & \\
TEMP (xi4) & 17 & 9.07 & 4.67 & 3.14 \\
\hline
\end{tabular}


Table 4: computed f-statistic for the climatic parameters. The degrees of freedom (df) is the same as in table

\begin{tabular}{lcccc}
\hline \multirow{2}{*}{ Parameter } & $\begin{array}{c}\text { Computed f } \\
\text { Statistic }\end{array}$ & \multicolumn{3}{c}{ Interpretation of results at: } \\
\cline { 3 - 5 } & 1.13 & $\mathbf{1 \%}$ & $\mathbf{5 \%}$ & $\mathbf{1 0 \%}$ \\
\hline Onset (xi1) & 2.525 & $\mathrm{NS}$ & $\mathrm{NS}$ & $\mathrm{NS}$ \\
LGS (xi2) & 24.178 & $\mathrm{~S}$ & $\mathrm{NS}$ & $\mathrm{NS}$ \\
Rainfall (xi3) & 5.985 & $\mathrm{NS}$ & $\mathrm{S}$ & $\mathrm{S}$ \\
Temp (xi4) & $\mathrm{N}$ & $\mathrm{S}$ \\
\hline
\end{tabular}

The degrees of freedom (df) is the same as in Table 4: S represents "Significant", and NS

"Notsignificant"

Furthermore, rainfall and temperature (temp), proved to be significant at almost all the three significant levels except at $1 \%$, where, as it turns out, temperature is not significant. These findings are supported by the work of Ifabiyi, et al. (2011) were they found a corresponding relationship between rainfall amounts and yield in Kwara State. Akintola (1983) and Ado (2005) observed a corresponding relationship between rainfall and maize production.

The associated $\mathrm{p}$ values presented in table $4.3 \mathrm{c}$ clearly agree with these results. Similarly, under t-test, the results are clearly in agreement with those above.

Table 5 p-values for the climatic parameters

\begin{tabular}{lcccc}
\hline \multirow{2}{*}{ Parameter } & $\begin{array}{c}\text { P values under f- } \\
\text { distribution (\%) }\end{array}$ & \multicolumn{3}{c}{ Interpretations of p values in relation to significant levels: } \\
\cline { 3 - 5 } & 30.72 & $\mathbf{1 \%}$ & $\mathbf{5 \%}$ & $\mathbf{1 0 \%}$ \\
\hline Onset (xi1) & 13.61 & $\mathrm{NS}$ & $\mathrm{NS}$ & $\mathrm{NS}$ \\
LGS (xi2) & 0.03 & $\mathrm{~S}$ & $\mathrm{~S}$ & $\mathrm{NS}$ \\
Rainfall (xi3) & 2.94 & $\mathrm{NS}$ & $\mathrm{S}$ & $\mathrm{S}$ \\
TEMP (xi4) & & & \\
\hline
\end{tabular}

Table 6 : critical values for t-statistic at n-1 degrees of freedom (df)

\begin{tabular}{lcccc}
\hline \multirow{2}{*}{ Parameter } & Degrees of freedom & \multicolumn{3}{c}{ Critical values for t-statistic } \\
\cline { 2 - 5 } & $\mathbf{n - 1}$ & $\mathbf{1 \%}$ & $\mathbf{5 \%}$ & $\mathbf{1 0 \%}$ \\
\hline Onset (xi1) & 17 & 9.07 & 4.67 & 3.14 \\
LGS (xi2) & 17 & 9.07 & 4.67 & 3.14 \\
Rainfall (xi3) & 17 & 9.07 & 4.67 & 3.14 \\
Temp (xi4) & 17 & 9.07 & 4.67 & 3.14 \\
\hline
\end{tabular}


Table 7: computed t-statistic for the climatic parameters. Degrees of freedom is the same as in Table (6)

\begin{tabular}{lcccc}
\hline Parameter & $\begin{array}{c}\text { Computed } \mathbf{t}- \\
\text { statistic }\end{array}$ & $\mathbf{1 \%}$ & Interpretation of results at: & \\
\hline Onset (xi1) & 1.2508 & NS & N\% & $\mathbf{1 0 \%}$ \\
LGS (xi2) & 1.8696 & NS & NS & NS \\
Rainfall (xi3) & 5.7859 & S & S & S \\
Temp (xi4) & 2.8786 & NS & S & S \\
\hline
\end{tabular}

S represents "Significant", and NS "Not significant".

Under the second approach presented in tables 8 and 9, two parameters were tested simultaneously for significance, thus retaining the two other parameters in the equation. In this way, and again, only rainfall and temperature proved significant at the $10 \%$ and $5 \%$ levels of significance under the f-test (table 8 and 9). The associated p-values presented in table 10 are also clearly in agreement with these observations.

Table 8. Critical f-statistic for the climatic parameters at $\mathrm{q}$ and $\mathrm{n}-\mathrm{k} \mathrm{df}$

\begin{tabular}{lccccc}
\hline Parameter & \multicolumn{1}{c}{$\begin{array}{c}\text { Degrees of } \\
\text { freedom }\end{array}$} & \multicolumn{2}{c}{ Critical values for f-statistic at: } \\
\cline { 2 - 6 } & $\mathbf{q}$ & $\begin{array}{c}\mathbf{n -} \\
\mathbf{k}\end{array}$ & $\mathbf{1 \%}$ & $\mathbf{5 \%}$ & $\mathbf{1 0 \%}$ \\
\hline $\begin{array}{l}\text { Onset \& } \\
\text { LGS }\end{array}$ & 2 & 13 & 6.70 & 3.81 & 2.76 \\
$\begin{array}{l}\text { Temp and } \\
\text { rainfall }\end{array}$ & 2 & 13 & 6.70 & 3.81 & 2.76 \\
\hline
\end{tabular}

Table 9. Computed f-statistic for the climatic parameter, df is same as in Table 8.

\begin{tabular}{|c|c|c|c|}
\hline \multirow[t]{2}{*}{ Parameter } & \multirow{2}{*}{$\frac{\text { Computed f - }}{1 \%}$} & \multicolumn{2}{|c|}{$\begin{array}{l}\text { Interpretation of results } \\
\text { at: }\end{array}$} \\
\hline & & $5 \%$ & $10 \%$ \\
\hline $\begin{array}{l}\text { Onset and } \\
\text { LGS }\end{array}$ & $1.755 \mathrm{NS}$ & NS & NS \\
\hline $\begin{array}{l}\text { Temp and } \\
\text { rainfall }\end{array}$ & $14.4 \mathrm{~S}$ & $S$ & $S$ \\
\hline
\end{tabular}


Table 10: $\mathrm{P}$ values for the climatic parameters and interpretation of the results.

\begin{tabular}{|c|c|c|c|c|}
\hline \multirow{2}{*}{ Parameter } & \multirow{2}{*}{$\begin{array}{l}\text { P values } \\
\text { under } t- \\
\text { distribution } \\
(\%) \\
\end{array}$} & \multicolumn{3}{|c|}{ Interpretations of $p$ values in relation to } \\
\hline & & $\underline{1 \%}$ & $5 \%$ & $10 \%$ \\
\hline $\begin{array}{l}\text { ONSET } \\
\text { and LGS }\end{array}$ & 21.5 & NS & NS & NS \\
\hline $\begin{array}{l}\text { TEMP and } \\
\text { Rainfall }\end{array}$ & 0.05 & NS & S & S \\
\hline
\end{tabular}

The three different parametric tests carried out following the two approaches found that only rainfall and temperature as climatic parameters could reasonably affect maize production to about $74 \%$ of the time, and thus can be retained as the only climatic parameters in the model. And so the resulting equation becomes :

$$
y i=-4571259.626-445.836 x i 1+227234.129 x i 2 \ldots \ldots \ldots[19]
$$

Here, xi 1 and $x i 2$ reprsents rainfall and temperature respectively, yi is maize yield, $i=1$ to 18

\subsection{The Multiple Linear Regression Model for Predicting Maize Production}

Having demonstrated that the model and some of its essential components exists using statistical tests, the model was then validated or evaluated in order to ascertain its level of performance vis-à-vis how it is able to replicate actual yield using only rainfall and temperature as the inputs.

Using eqn19 and with $\mathrm{y}_{\mathrm{i}_{\text {model }}}$ as modelled maize production in eqn18, it was found that the coefficient of determination of the model is 0.742 or $74 \%$. This implies that over $70 \%$ of the actual variations in maize production (within the period under review, 1999-2016), can be explained by the MLR model, the model for maize prediction is therefore given as

$y i=-3758856.21+156743.46 x i 1-443.79 x i 2 \quad \ldots . .[20]$

Here,xi1 and xi 2 represents rainfall and temperature respectively, yi is maize yield, $i=1$ to $18 \quad$ with rainfall and temperature as inputs.

Additionally, the standard error based on the Table 11 was computed using eqn 17 and found to be 0.805 , implying that the amount of error that is likely to result from using the model (eqn18b) to forecast maize production (per 100,000 of hectares) in any year is within the interval 0.805 . Furthermore, the $95 \%$ confidence interval margin using this value is $\pm 1.96 \times 0.805= \pm 1.6$. Thus the $95 \%$ confidence interval for yield in any given year is $y_{\text {modeli }} \pm 1.6$. This implies that for any given year, there is $95 \%$ probability the yield generated from this model is within the interval $y_{\text {modeli }} \pm 1.6$. 
The coefficients of correlation were also computed from table 11 and found to be 0.86 . This indicates that the degree of the linear relationship between maize yield, on the one hand, and temperature and rainfall on the other, is thus quantified as 0.86 . The year 2017 and 2018 were used as focal point to generate a forecast for the aforementioned year and the forecast generated is presented therein.

Table 11: Actual and Forecast Maize Production from 1999-2016 using MLR Model

The results are presented per 100,000 hectares.

\begin{tabular}{lcc}
\hline Year & Actual maize yield $\left(\mathrm{y}_{\mathrm{i}}\right)$ & Forecast maize yield $\left(\mathrm{y}_{\mathrm{i}}\right.$ model \\
& & ) \\
\hline 1999 & 7.0 & 6.6 \\
2000 & 5.5 & 6.6 \\
2001 & 5.5 & 7.2 \\
2002 & 5.5 & 6.4 \\
2003 & 5.5 & 4.8 \\
2004 & 6.4 & 7.2 \\
2005 & 8.7 & 8.8 \\
2006 & 9.0 & 9.3 \\
2007 & 9.7 & 8.4 \\
2008 & 9.9 & 9.3 \\
2009 & 10.1 & 7.7 \\
2010 & 8.0 & 7.4 \\
2011 & 7.2 & 7.4 \\
2012 & 7.2 & 5.9 \\
2013 & 7.9 & 5.9 \\
2014 & 6.2 & 6.1 \\
2015 & 6.2 & 5.9 \\
2016 & 6.4 & 7.3 \\
2017 & 8.6 & 7.1 \\
2018 & - & 8.3 \\
\hline
\end{tabular}

The results are presented per 100,000 ha.

\subsection{Conclusion}

The data points were aggregated into their monthly and subsequently annual values in order to investigate the trends therein. The standardized annual precipitation index for the rainfall distribution and temperature departure was computed. There was a slight increase in annual rainfall and a significant increase in average annual temperature during the period covered by this study in Kaduna State. Rainfall amount ranged between lowest value of $793.4 \mathrm{~mm}$ in 2008 and highest value of $1658.9 \mathrm{~mm}$ in 2014. During the period, average annual rainfall amount was $1279.4 \mathrm{~mm}$. There was a high coefficient of inter annual variation of about $21 \%$ during the period of study. Over all, there was a marginal increase in rainfall amount though not statistically significant (1.4499). The t-test carried out showed that there was an increase in annual rainfall and annual average temperature with the latter significant at the 1 and 5\% levels (this corresponds to a calculated $t$ value of 2.6234). The temperature departure from the normal showed that in 
2016, the highest positive departure was observed with an anomaly of $+2.39^{\circ} \mathrm{C}$ while the least deviation was in 2001 with an observed departure of $-1.75^{\circ} \mathrm{C}$. The onset and cessation of rainfall was determined following the Walter's formulation, with some modifications by Olaniran (1983) and it was observed that the lowest and latest onset dates observed in Kaduna State was on the $17^{\text {th }}$ March, 2016 and $13^{\text {th }}$ of May, 2006 respectively. Subjected to statistical test, the departure in onset dates in Kaduna was found not to be significant at the $1 \%$ and $5 \%$ level of significance. The departure in the onset dates showed that there has been early onset of the rains in the state. Similarly, results of the cessation dates showed cases of early cessation when compared to the average cessation dates. Analysis of the length of the growing season revealed that in 2001, 2004, 2007 and 2008, a remarkable decrease in LGS were observed, while in 2002, 2003, 2005, and 2014, an increase in LGS were observed. On the average, LGS was about One Hundred and Sixty days (160) during the period under review. A multiple regression analysis carried out to ascertain the relationship between maize production and the meteorological parameters, namely temperature, rainfall, and onset, showed a coefficient determination of 0.742 . The resulting equation was then derived. Additionally, the significance of the whole multiple linear regression (MLR) model was carried out to ascertain if a linear relationship exists between the yield and the other climatic parameters in the first place. The computed f-ratio was found to be 9.358, while the critical value of the f-ratio was found to be 3.17. Apparently, the computed f-ratio (9.358) is greater than its critical value (3.17) indicating that the model is significant at $5 \%$ level of significance. The significance of the model was also tested at $1 \%$ and $10 \%$ both of which agreed that the model is significant. Thus, in other words, a linear relationship exists between maize yield and the four climatic variables. This is also backed by the associated $\mathrm{p}$ value $(0.09 \%)$ which is less than all the highlighted levels of significance, indicating that the null hypothesis $\left(\mathrm{H}_{0}\right.$, which states the "MLR model is not significant/the coefficients of the model are not significant"), can be rejected.

The level of significance of the individual parameters were then tested to ascertain which one of the climatic parameters contribute to maize production using the F-test and t-test at the 1\%,5\% and 10\%, level of significance. This approach proved that the onset dates and length of the growing season (LGS) are not significant at all the three chosen levels of significance. However, rainfall amount and temperature were shown to be significant contributors to maize production at almost all the three significant levels except at $1 \%$, where, as it turns out, temperature is not significant. On the basis of the aforementioned, a model for predicting maize production with temperature and rainfall as the major input was developed. Similarly, the coefficient of determination of the model was found to be 0.67 or $67 \%$. This implies that over $65 \%$ of the actual variations in maize production (within the period under review, 19992016), can be explained by the MLR model using only temperature and rainfall as the input parameters.

The study concludes that there has been an increasing trend in rainfall and temperature observed in Kaduna State. Rainfall amount ranged between lowest value of $793.4 \mathrm{~mm}$ in 2008 and highest value of $1658.9 \mathrm{~mm}$ in 2014, with an inter annual coefficient of variability of $21 \%$. The significance of trend for temperature reveals a significant upward trend at the 1 and 5\% levels (2.6234). Early onset and cessation dates were observed during the period covered. An analysis of the regression model using f-test to test for significance of each of the variables revealed a significant relationship between rainfall amount and temperature with maize production. The results also show that rainfall and temperature amounts have the strongest influence on maize production in the study area. 


\section{REFERENCES}

Ado, S. G., Showemimo, F. A., Alabi, S. O., Badu-Apraku, B., Menkir, A., Usman, I. S. and Abdullahi, U. S. 2005. Maize research at IAR Samaru. In Badu Apraku, B., Fakorede, M. A. B., Lum, A. F., Menkir, A. and Ouedraogo, M. (eds) Demand-Driven Technologies for Sustainable Maize Production in West and Central Africa. Scientific papers presented at the regional workshop of the West and Central Africa Collaborative Maize Research Network (WECAMAN) held at IITA-Cotonou, Benin, 3-6 May 2005. Ibadan: IITA. pp 107-120.

Ayansina, A., Ogunbo, S. 2009. GIS Approach in Assessing Seasonal Rainfall Variability in Guinea Savanna Part of Nigeria, 7th FIG Regional Conference, Vietnam, 19-22 October 2009 pp.16.

Allen, L.H., Pan, D., Boote Jr., K.J., Pickering, N.B., Zimbabwe 2010. Carbon dioxide and temperature effects on evapotranspiration and water use efficiency of soybean. Agron. J., 95: 1071-1081.

Akintola, J. O. 1983. An Analysis of the Effects of Agroclimatic Factors on Food Crop Yields in Ibadan Area of Oyo State, Unpublished Ph.D Thesis, University of Ibadan, Ibadan.

Aremu, O, Bello, E., Aganbi, B., Festus, O. 2017. Trend analysis and change point detection of rainfall across agroecological zones for sustainable development in Nigeria. Environmental risk assessment and remediation 2017, Volume 1, Issue 2, pg 36-46.

Brett, H. 2009. Food and Agriculture, Features, Climate Change Threat to Food Security. Available at http://www.people and planet. Net/doc. Php? Id = 3482. De Chavez and Tauli-Corpus (eds.) (2008). Guide to climate change. Retrieved on 26th June, 2009 from www.tebtebba.org.

Diallo, A. O., Edmeades, G. O. and Johnson, E. C. 1989. Breeding strategies to overcome constraints and increase maize producitivity in Sub-Saharan Africa. In Gebrekidan, B. (ed) Maize Improvement, Production and Protection in Eastern and Southern Africa. Proceedings of the Third Eastern and Southern Africa Regional Maize Workshop held 18-22 September at Nairo-Ketale, Kenya.

FAO 2010. FAO statistical database. Rome: Food and Agricultural Organization of the United Nations (FAO).

FRN (Federal Republic of Nigeria) 2000. National Action Program (NAP) to Combat Desertification and Mitigate the Effect of Drought. Towards the Implementation of the United Nations Convention to Combat Desertification and Mitigate the Effect of Drought in the Country

Ifabiyi, I.P., Omoyosoye, O. 2011. "Rainfall Characteristics and Maize Yield in Kwara State,” Nigeria. Journal of Applied Sciences, Vol. 1, No. 3. 
Intergovernmental Panel Climate Change (2007a) Climate change 2007. The fourth assessment report (AR4). Synthesis report for policy makers http://www.ipcc.ch/pdf/assessmentreport/ar4/syr/ar4-syr-spm.pdf. Accessed 10th August, 2009.

Jones, P.G. and Thornton, P.K. 2003. The Potential Impacts of Climate Change on Maize Production in Africa and Latin America in 2055. Global Environmental Change, 13,51-59. https://doi.org/10.1016/S09593780(02)00090-0.

Kandji, S.T, Verchot, L. and Mackensen, J. 2006. Climate change and variability in the Sahel region: Impacts and adaptation strategies in the agricultural sector, 58. http://www.unep.org/. Accessed 5 April 2014.

Nigerian Meteorological Agency climate Review 2017. Climate Review

Nigerian Meteorological Agency 2018. Annual Seasonal Rainfall Prediction

National Population Commission (NPC) 2006. Nigerian Population Census Report. National Population Commission, Abuja, 21-27.

Odekunle, O. T., Andrew, O., Aremu, O. S. 2008. Towards a Wetter Sudano-Sahelian Ecological Zone in the TwentyFirst Century Nigeria. Weather, 63(3), 66-70. http://dx.doi.org/10.1002/wea.172.

Oladipo, E. O. 1993. A comprehensive approach to drought and desertification in Northern Nigeria. Nat. Hazards, 8: 235-261.

Olusegun, A., Bello, E., Aganbi, B., Festus, O. 2017. Trend analysis and change point detection of rainfall across agro-ecological zones for sustainable development in Nigeria. Environmental risk assessment and remediation 2017, Volume 1, Issue 2, pp. 36-46.

Thompson, A.M., Brown, R.A., Rosenberg, N.J., Izaurralde, R.C., Benson, V. 2005. Climate change impacts for the conterminous USA: an integrated assessment Part, 3. Dryland production of grain and forage crops. Clim Change 69:43-65.

Yesuf, M., Difalce, S., Riungler, C., Kolhlim, G. 2008. The impact in climate change and Adaptation on Food Production in Low-income countries: Evidence from the Nile Basin, Ethiopia, International and Production Technology Division, IFPRI, Washington D.C. 